\title{
ENVISIONING EVERYDAY LIFE: EXPLORATIONS OF VISUALIZATION TECHNIQUES IN TAIWAN
}

Wei-Kuang Liu

School of Arts, Culture and Environment

University of Edinburgh

20 Chambers Street

Edinburgh EH1 1JZ

United Kingdom

wei.kuang@ed.ac.uk

http://www.ace.ed.ac.uk

\begin{abstract}
This paper introduces my exploration of techniques that attempt to methodically visualize everyday life so as to allow cultural context to be transferred into a comparable and discussible form. Although, everyday tactics are of dynamic flows that cannot be notated structurally, they can be depicted. The visual depiction is formed on an objective and integrated temporal scale structure so as to represent the rhythm of flows properly. Then, the paper describes a series of visual maps that represent the way three temple courtyards in the city of Tainan, ancient capital of Taiwan, are used over a 24-hour period.
\end{abstract}

\section{INTRODUCTION}

This paper attempts to envision the practices of everyday life so that the processes of producing geographic cultural characteristics can be compared and discussed. The meaning of culture is varied, yet here, culture mainly refers to the ways of life in certain space and time that create identifiable sense of place. In other words, the characteristics of culture in the place are derived from the practices of everyday life. Scholars working on geography and urban history, such as Crang, Tuan, and Conzen, have argued that the sense of place in a given situation resides in the atmosphere, narratives, character, quality and genius loci of the environment, and that this creates the locality and the identity of the social context in the place [1]. Thus, as Massey suggests, the place is not only the effect of civilization, but cultural process [2]. It is always becoming and never become [3]. Understood in this way, as architect Stan Allen notes, the concept of time is just as significant in the appreciation of place as space. If there was no time, spaces would be just left empty without stories [4]. In addition, everyday life cannot be defined precisely as there is no authenticity of ways of life. Its meaning is only identifiable relatively, by comparing with different cultures [5]. So we must develop comparative methodologies for the study of everyday life.

The best way to represent the everyday life is to show its original sense perceptions of the place, rather than to narrate it merely through some texts and diagrams, so that the representation can transmit something of the original experiences of the place more effectively. In addition, visual perceptions can always convey more significant emotional impacts than what other perceptions can do. As Crang argues, it can, with seeming effortlessness, bring the audiences back to the scene in an ontology that privileges the visible realities; in an epistemological sense, the visualization of data also 
provides visual metaphors to constitute the truth claims. Thus, visual methodologies are always the most proper manners to represent the nature of everyday cultures [6].

Cinema, argues Deleuze, is the most successful visual form to depict the dynamic structure of the place. Cinema represents the dynamic contexts by speedily delivering sequential immobile visual sections with equidistant durations [7]. The representation strategically reorganizes the everyday stories, experiences, and emotions of one place, so that they can be perceived widely in different places. However, the cinematic narrative texts are often so unsystematic, subjective, and fragmentary, and they are rarely appropriate to comparative methods for the everyday dynamic structure study. As a result, this paper introduces my explorations with techniques that methodically visualize everyday life based on cinematic principles so as to allow the cultural context to be transferred into a comparable and discussible form.

In order to grasp the variable patterns of everyday life for comparative studies, this paper will then explore the everyday life theories firstly. Afterwards, some forms of visualization that have been used to represent dynamic structures will be illustrated, and they will be conducive to the study of the comparative visual methodologies. Eventually, the everyday life of some temple courtyards in the historic city centre of Tainan, ancient capital of Taiwan, will be depicted with the techniques so as to explain how the visual methodologies work.

\section{EVERYDAY LIFE THEORIES}

In order to grasp the genius of a given place, we have to depict the practices of everyday life that are played out there. Such depictions will enable us to understand the interrelation between the environmental and everyday social contexts. To this end, we must explore the everyday life theories.

In fact, every element in our living space influences people's behaviours because we have learnt to interact with it. All the symbolic signals in the city constitute the consequential models of behaviours. Many sociologists point to the routinized character of contemporary everyday life has become. For example, we repeat our commutes from our homes to the work places while we can always unconsciously react with various traffic situations. Thus, the ways of our everyday life are almost dominated by the urban systems. This concept implies that the forms of our living culture are decided by the characteristics of the place. Simmel deems that our abilities of negotiating with the everyday life have collapsed due to the metropolitan impacts on human perceptions [8]. Jameson describes the contemporary cultural form as an instinctive mode of reaction without individual consciousness, and that is thoughtless and hollow [9]. Lefebvre indicates that our everyday life is ruled by the social context of the modern capitalism, and he adds that this phenomenon is the alienation of everyday life [10].

Lefebvre therefore argues that we must de-alienate our everyday life through cultural revolutions, such as festivals. Festivals resist the alienation by strong consciousness of cultural traditions and liberate our life from the urban domination [11]. However, de Certeau has different opinions although he also agrees that our everyday life is alienated. He argues that our everyday life is impossible to be alienated absolutely because the power of de-alienation always lurks in our everyday life to resist the phenomenon of alienation [12]. Moreover, he introduces the theory of strategy and tactic to explain the interrelation between alienation and de-alienation. While the strategies of everyday life are of the unconscious behaviours dominated by the urban systems, the everyday tactics are of the subconscious behaviours resisting the 
domination [13]. If our everyday life was totally alienated, then we could easily presume and predict human behaviours according to the urban systems. But as people sometimes walk through the lawn where is no pavement and sit on the stair where is supposed to be the vertical circulation, there are in fact plenty of unpredictable tactics resisting the alienation of everyday life.

The everyday tactics are the behaviours of consuming the production of space. Consumption is not only an act of using, but also the process of producing. In other words, it is the process of reproducing the meaning of the product [14]. When lots of people walk through the lawn by the same track, there will be a path appeared which redefines the meaning of the place. Deleuze explains the nature of consuming acts through the theory of rhizome: the form of a plant always depends on the underneath invisible network of roots. This metaphor shows the sense of place is derived from the idiosyncrasies and processes of daily stealthy human reappropriations of everyday spaces [15]. As a result, the form of place and its everyday living culture are in fact interdependent to each other [16]. The place forms the strategy of everyday life, while the meaning of the place is produced from the everyday tactics. Therefore, we must depict these everyday tactics so as to describe the sense of place.

However, the practice of everyday life is of subconscious behaviour that is unpredictable and different everyday. Thus, as Highmore argues, to depict one's everyday life is as difficult as to explain the dreams [17]. Yet, if these acts of reappropriation can be envisioned jointly and intensively by certain methodical models, we will be able to describe the everyday life [18].

\section{VISUAL NARRATIVES}

As has been mentioned earlier, there is no authenticity of ways of life, so everyday life cannot be represented precisely and structurally. Yet the representation can form a narrative style. In addition, the representation is to describe the fact, not to show the agreement, as the meaning of everyday life is different to everyone. Therefore, the representation techniques must be fairly objective.

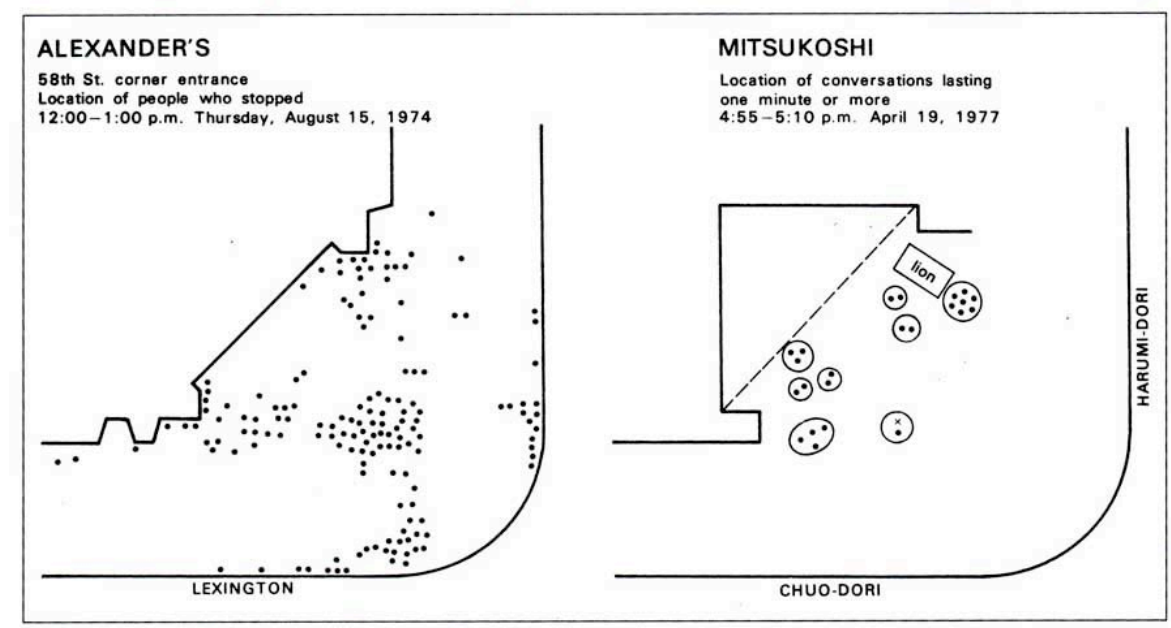

Figure 1. Analytic maps of environmental behaviour research [19]

Since the everyday tactics consist of the event of reappropriating the space and the time of everydayness, the study of everyday life focuses on the interrelations between events and time. Thus, we need to create a platform for the representation of the patterns 
of their interactions. Obviously, those common architectural representation techniques including the drawings of plan, section, and elevation cannot depict these contexts [20]. Furthermore, the empirical theories of environmental behaviour always focus on the relations between behaviours and the social contexts that form the event structure, rather than the interactions between events and the everyday time (Figure 1). In addition, these sociologists attempt to quantify the events for statistical methodologies rather than to represent the stories of event. Those statistical tables never tell the everyday stories.

Yet, cinema can represent the interrelations between events and time. It reproduces the real movements through the principles of 'immobile sections + abstract time'. The immobile sections are not merely photos, but equidistant snapshots. The equidistance is transferred on to a framework as the mechanism to constitute the film [21]. Yet, the reproductions of real movements constituted by visual illusions are reckoned as fakes in phenomenological sense, so the nature of reality cannot be perceived [22]. However, philosopher Henri Bergson is opposed to this argument. In 1907, he said, in Creative Evolution, that' We take snapshots...these are characteristics of the reality, we have only to string them on a becoming abstract, uniform and invisible, situated at the back of the apparatus of knowledge...Perception, intellection, language so proceed in general.' [23] The result is not always artificial when the means are artificial. The false movements can certainly transmit the natural perceptions by visual illusions because they have never been noted that what they give us is the photogramme, the immobile sections of 24 images per second [24]. Thus, through cinematic representations, the everyday stories can be visually perceived by the audiences.

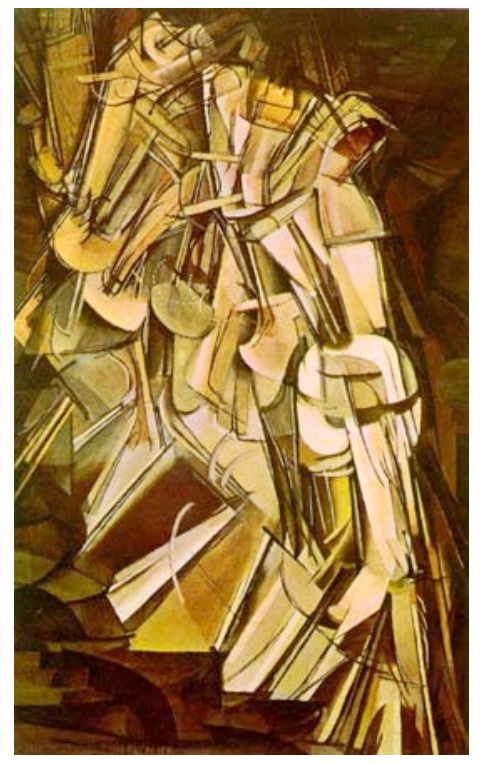

Figure 2. Marcel Duchamp. Nude Descending a Staircase, No. 2 (1912)

Although cinema can represent our everyday life, the filmic representations are hardly appropriate to comparative methodologies as they are often so unsystematic, subjective, and fragmentary. Thus, we must develop a methodical strategy based on the cinematic principles. 'Nude Descending a Staircase', painted by cubist artist Marcel Duchamp in 1912, captures the dynamic movement in a picture (Figure 2). In fact, it applies the cinematic principles of representing the movement by delivering sequential immobile visual sections. Dance notation system also provides a clue to create this event-time representation platform. It systematically narrates the dynamic experiences 
of dance through notations on a well-ordered linear time scale to show the interrelations between events and time [25]. Furthermore, the Dutch architect Rem Koolhaas develops a diagram in his Yokohama urban design project to represent the relations between everyday events and the time scale of 24-hour, yet it merely shows the intensity of the events rather than the stories (Figure 3). All the above examples illustrate certain events and their relations with time successfully. In fact, all of them are equipped wellstructured temporal frameworks for the depictions of events. Accordingly, the visual depictions of everyday tactics must be formed on an objective and integrated temporal scale structure so as to represent the rhythm of flows properly.

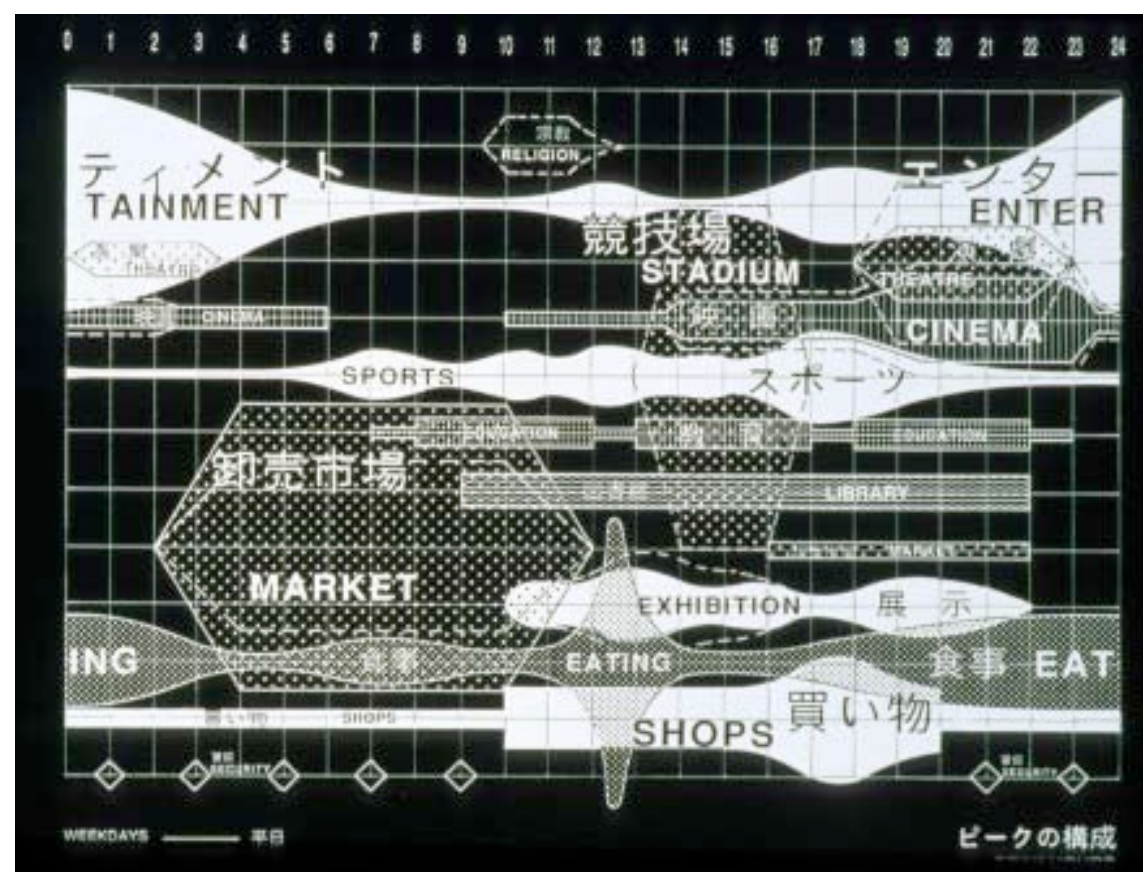

Figure 3. The configuration of event-time programmes [26]

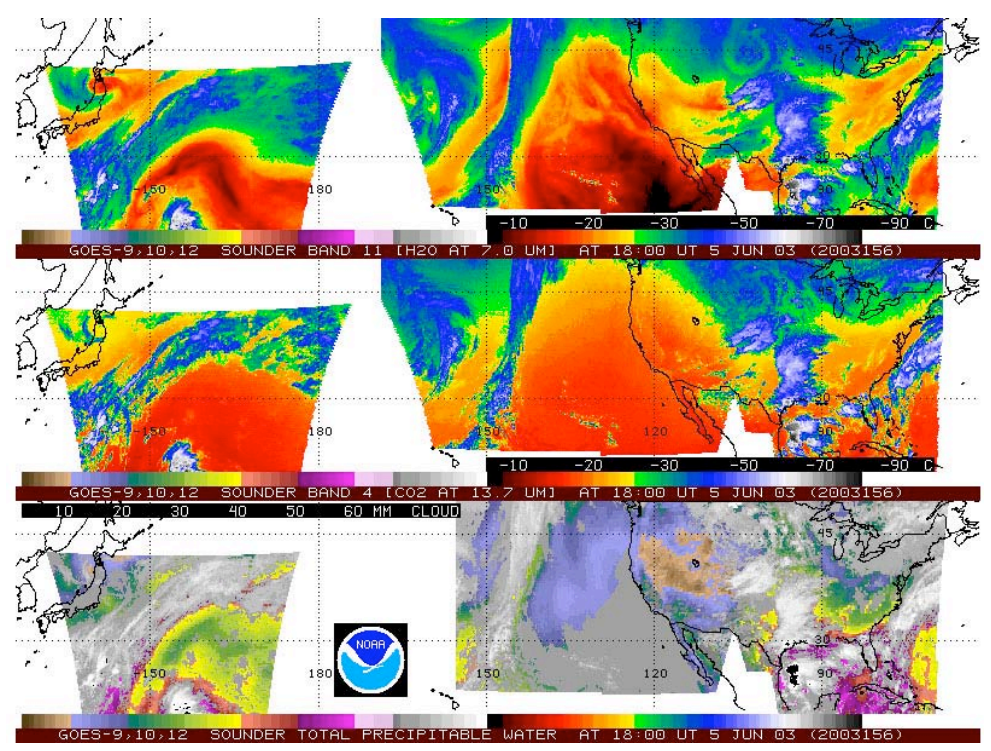

Figure 4. Meteorological map: weather events notation system [27] 
In addition, the sense of place cannot be represented objectively and systematically since it is changed everyday. Thus, the visual depictions can only narrate one day of life rather than the general concept of everyday place. Then, through the methodical representation platforms, the one day lives in different places or different dates can be compared and discussed. Such depictions are just like the meteorological maps that notate the events of weather changes during a day in a particular place, so that the unpredictable and unmappable events in the place can be shown through this notation platform for further comparative studies (Figure 4).

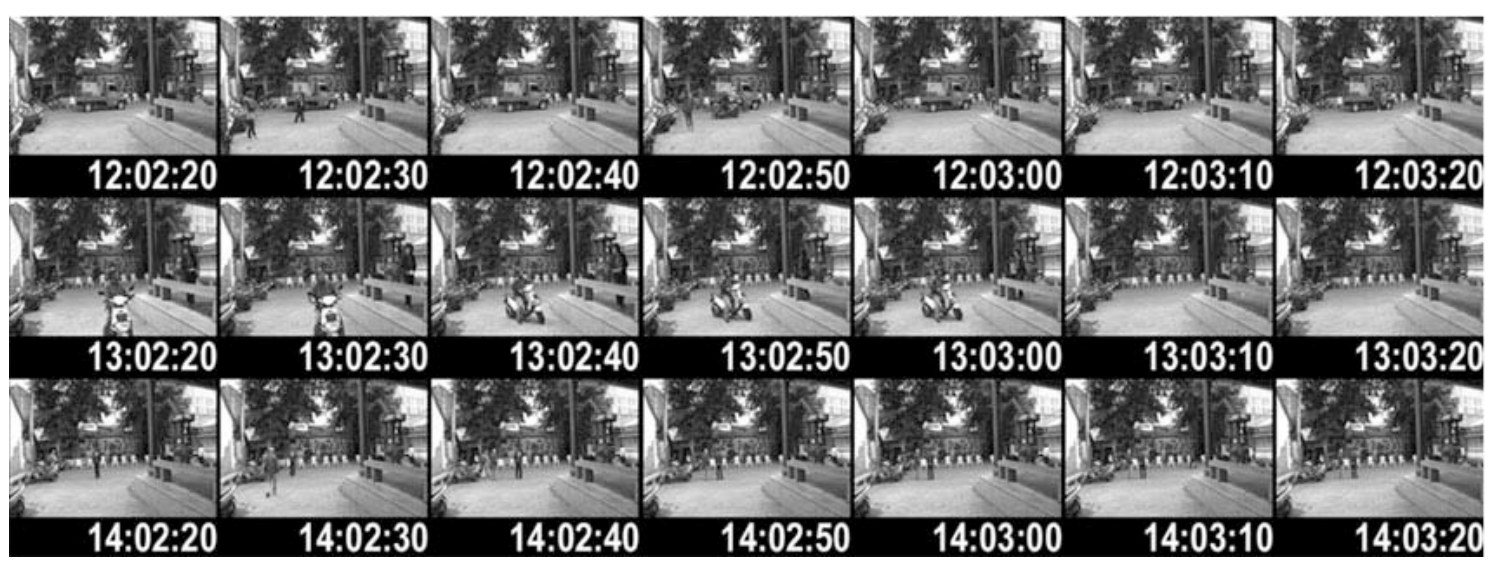

Figure 5. The equidistant snapshots

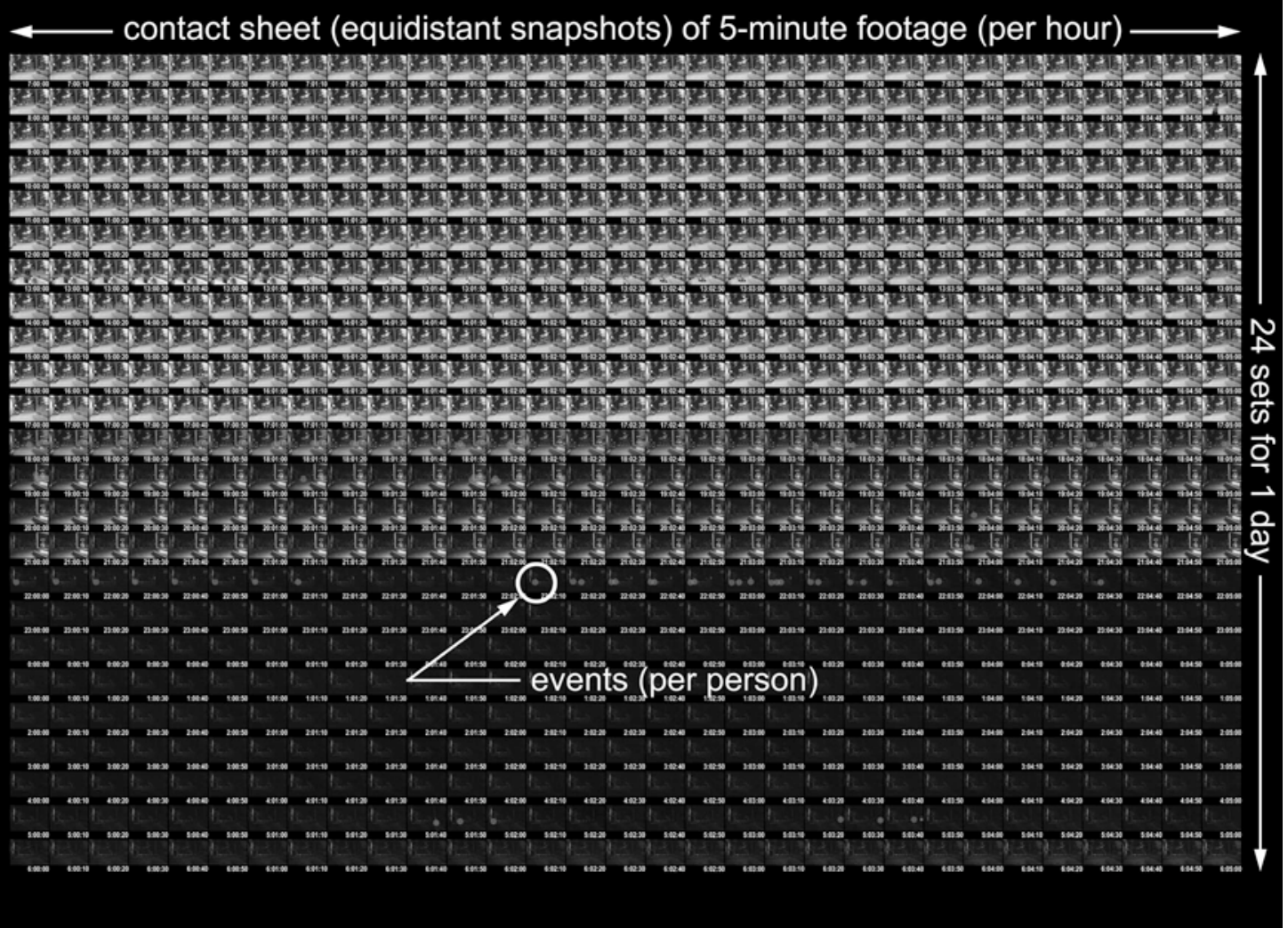

Figure 6. 24-hour event-time notation system 
Since cinema can reproduce the movements by the principles of 'immobile sections + abstract time', the one day of life of the place can be methodically represented by the same principles. As has been mentioned, the immobile sections must be equidistant snapshots because the equidistant temporal framework is an essential mechanism to reproduce the movements. Thus, we can also take equidistant snapshots to represent the 24-hour stories of the place (Figure 5). The depicting form is represented as a contact sheet of the original 24 sets ( 1 set per hour) of 5 -minute footage. We film the place for 5 minutes each hour. The duration of 5 minutes is appropriate for studies, while it does not interfere with the life too much. Also, they must be taken at the same section of each hour to ensure the equidistance, and taken from the same position to allow the continuity of the representations. Each set of the 5-minute footage is divided by the interval of 10 seconds to get 31 equidistant sequential snapshots represented as a contact sheet. The duration of 10 seconds is the average time of people walking through the video frame (distance of 15-25 meters). The interval cannot be longer, or some events will be missed out; if it is shorter, we will have too many snapshots. Then, 24 sets of them constitute the well-structured temporal framework of one day for the event notations. The events captured in the snapshots are notated with different colours according to the classifications, so that the interrelations between events and time can be shown. Thus, the cultural process in a given place can be studied comparatively through this notation platform (Figure 6).

\section{EVERYDAY LIFE VISUALIZATION}

According to the everyday life theories, the cultural quality of a given place can be produced not only by its local historical fabrics, but also by the human activities; while human act often changes the form of the city and generates meaning for the place through the everyday tactics of using the space. However, the human act is in fact influenced by the urban fabric, especially the functions of the setting. For example, the people's movements in a street would be different if the residence alongside changed to become factories or shops in the same location. Thus, urban changes influence the logic of act, while simultaneously human activity produces the place. Reciprocally, both affect each other enabling continuous change of the city and its culture.

This paper explores the everyday life of three temple courtyards in the city of Tainan through the visualization techniques so as to discuss the interrelations between the characteristics of the places and their everyday life styles. Tainan is the old capital of Taiwan and has rich historic characteristics with a multi-cultural colonial background. The older parts of its urban fabric, developed organically since the Dutch Colonial Era in the $17^{\text {th }}$ century, overlap with the modern urban plan developed in Japanese Colonial Era (1895-1945). Since, the urban structure has changed significantly. Yet, the social structure in the area still maintains an intimate interaction with the old fabrics.

Because land use is one of the essential factors that affect the urban form [28], the paper classifies Tainan's temple courtyards into three major categories according to their functions, namely, residential, semi-commercial, and commercial type. The Haian, Yunghua, and Zhonggan temple courtyards, that show strong features of each category, are chosen as paradigmatic case studies. Due to the multi-cultural colonial background, their surrounding fabrics changed dramatically during the last few centuries. Today, they are located in the city centre and situated in unique residential and commercial mixed fabrics. Because of different characteristics of their commercial settings, the three courtyards have developed very different living cultures. 


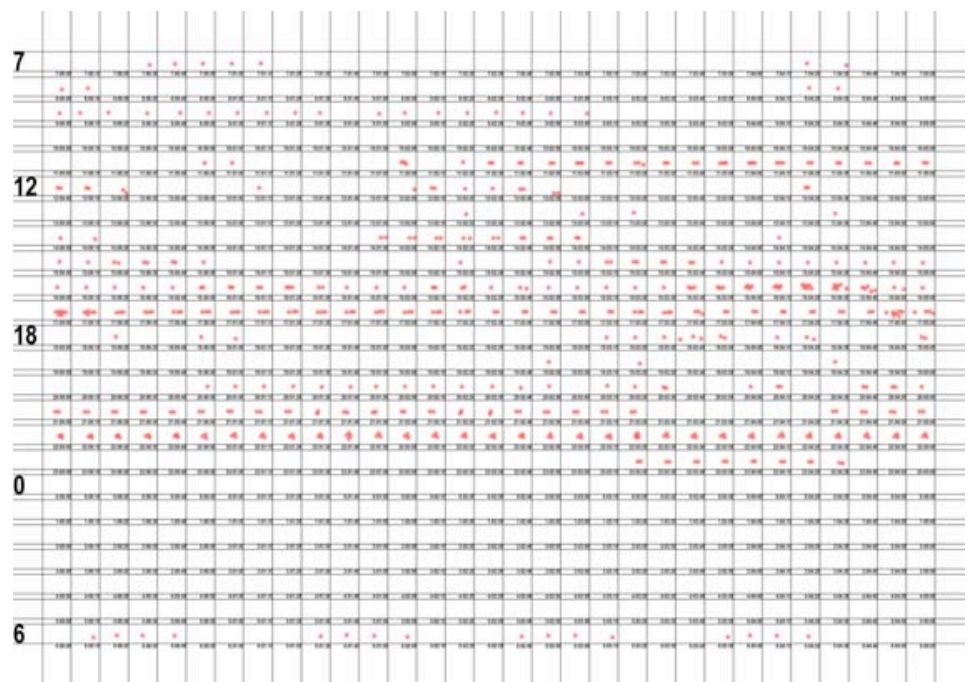

Figure 7. Haian Temple Courtyard: 7am 07/11/07 (Wed) - 6am 08/11/07

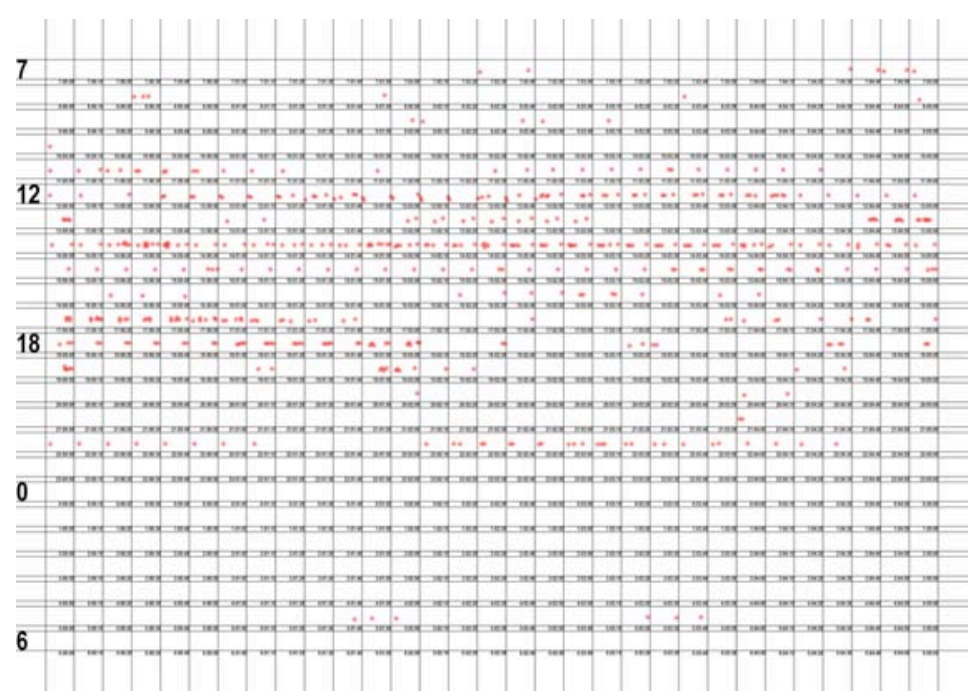

Figure 8. Ynghua Temple Courtyard: 7am 06/03/07 (Tue) - 6am 07/03/07

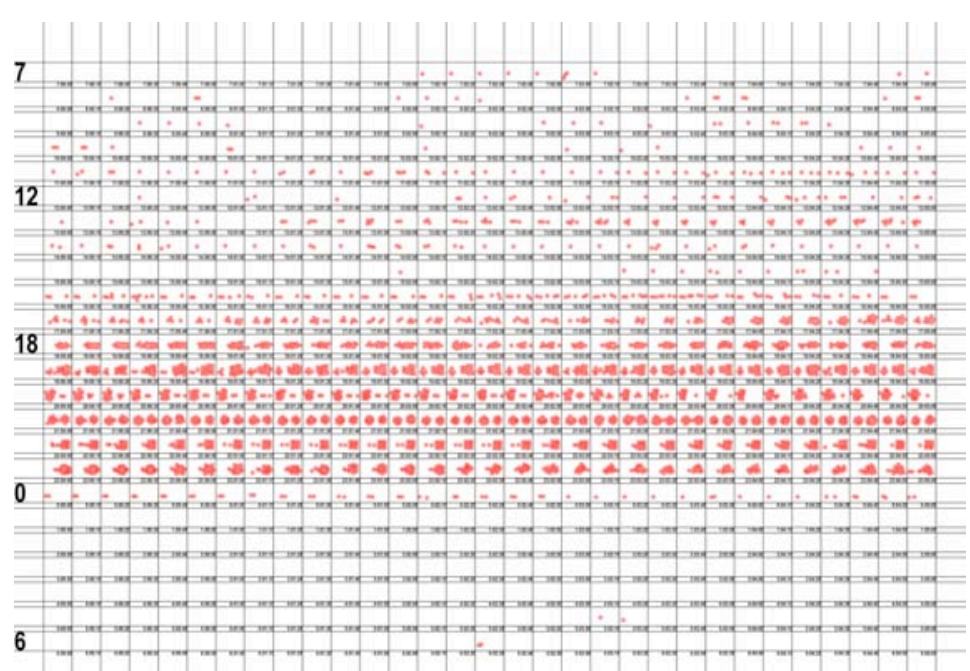

Figure 9. Zhonggan Temple Courtyard: 7am 07/11/07 (Wed) - 6am 08/11/07 
The surrounding area of the Haian Temple is mainly residential. There is hardly a shop in the courtyard and its connecting circulations. You can only find some grocery shops and eateries in the main roads outside the area. Thus, the temple courtyard almost becomes the private space for local community's leisure activities of exercise, play, private parking, chatting, and relaxation, which is very friendly to children and the old. The surrounding area of the Yunghua Temple is also quite residential, but more shops nearby. There are a few eateries in the courtyard and its connecting circulations. One of the major circulations connects with the Confucius Temple attractions and, thus, there are restaurants, bars, souvenir shops and antique shops; other circulations connect with a quiet residential area. So the temple courtyard is not only the space for community's activities of chatting and relaxation, but also the space for public parking, service parking, organized events, and visitors' rests. The Zhonggan temple is located in a busy commercial area. There is one grocery shop and one seafood bar in the temple courtyard, while almost half the courtyard is occupied by the seafood bar's tables everyday during the dinner time. There are many other grocery shops and eateries in the connecting circulations. In the surrounding main road, you can find banks, department stores, restaurants, markets, and all kind of high street shops. This temple courtyard becomes merely part of passing circulations for the local community, and there is hardly a leisure activity. Apart from the seafood bar's dinner service, the major activities in the courtyard are public parking, service parking, shops loading services, etc.

There are three 24-hour everyday life visual maps (Figure 7-9) that show the interrelations between general events (without classification) and time (7am-6am) in the temple courtyards. They are all done in weekdays with similar weather situations to enable the comparability. Through different colour notations, the maps can represent the differences of event contents, actors' origins (local or not), lasting time of acts, intention of acts (purposing to use the space or not), actor's sex and age, etc., as well as their relations with the time of 24-hour. Then the event-time relations of different places can be compared and discussed. Thus, the visual techniques effectively provide the platform for the comparative studies of everyday life. The methodologies can be applied to any other comparative everyday cultural studies regarding the sense of place.

\section{References}

[1] CRANG, M: Cultural Geography. London: Routledge, 1998, p.109; Conzen, M R G: Thanking About Urban Form: Papers on Urban Morphology, 1932-1998. Bern; Oxford: Peter Lang, 2004, pp.38-39; Jivén, G and Larkham, P J: Sense of Place, Authenticity and Character: A Commentary, Journal of Urban Design, vol. 8, 2003, pp.67-81; Tuan, Y: Space and Place: the Perspective of Experience. London: Edward Arnold, 1977, pp.5-6

[2] MASSEY, D: A Global Sense of Place. In T. J. Barnes and D. Gregory (eds.), Reading Human Geography: the Poetics and Politics of Inquiry. London: Arnold, 1997, pp.315-323

[3] PRED, A R: Place as Historically Contingent Process: Structuration and the Time-Geography of Becoming Places, Annals of the Association of American Geographers, vol. 74, 1984, pp.279-297

[4] The experience of urban life belongs more to time than to space. See Allen, S: Practice: Architecture, Technique and Representation. Amsterdam: G+B Arts International, 2000, p.42 
[5] HIGHMORE, B: Everyday Life and Cultural Theory : An Introduction. London: Routledge, 2002, p.177

[6] CRANG, M: Qualitative Methods: Touchy, Feely, Look-See? Progress in Human Geography, vol. 27, 2003, pp.494-504

[7] DELEUZE, G: Cinema I: the Movement Image. London: Athlone, 1986, pp.1-11

[8] SIMMEL G: On Individuality and Social Forms: Selected Writings. Chicago: University of Chicago Press, 1971, p.329

[9] JAMESON, F: Postmodernism, or, the Cultural Logic of Late Capitalism. London: Verso, 1991.

[10] LEFEBVRE, H: Everyday Life in the Modern World. London: Athlone, 2000, pp. $59-60$

[11] LEFEBVRE, H: Critique of everyday life. London: Verso, 1991, pp.202-203

[12] DE CERTEAU, M: Culture in the plural. Minneapolis; London: University of Minnesota Press, 1997, pp.137-138

[13] DE CERTEAU, M: The Practice of Everyday Life. Berkeley; London: University of California Press, 1984, pp.29-42

[14] Ibid. p.31

[15] DELEUZE, G and Guattari, F: A Thousand Plateaus: Capitalism and Schizophrenia. London: Athlone, 1988, pp.6-7

[16] The place influences the characteristics of the social (cultural) context, while the sense of the place is formed by the social context. See Malpas, J E: Place and Experience: a Philosophical Topography. Cambridge: Cambridge University Press, 1999, pp.35-36

[17] HIGHMORE, B: Everyday Life and Cultural Theory : An Introduction. London: Routledge, 2002, p.170

[18] Everyday life cannot be predicted and decided, but it can be depicted impressionistically. It is like taking snapshots of everyday life, but viewed from the aspect of eternity. See Simmel G: Simmel on Culture. London: Sage, 1997, p.109; Frisby D: Fragments of Modernity: Theories of Modernity in the Work of Simmel, Kracauer and Benjamin. Cambridge: Polity, 1985, p.71

[19] The study of the social lives of department store doorways in New York's Alexander's and Tokyo's Mitsukoshi. See Whyte, W H: The Essential William H. Whyte. New York: Fordham University Press, 2000, pp.230-231

[20] ALLEN, S: Practice: Architecture, Technique and Representation. Amsterdam: G+B Arts International, 2000, p.32

[21] DELEUZE, G: Cinema I: the Movement Image. London: Athlone, 1986, pp.4-5

[22] Ibid. pp.1-2

[23] BERGSON, H: Creative Evolution. New York: Random House, 1944.

[24] DELEUZE, G: Cinema I: the Movement Image. London: Athlone, 1986, p.2

[25] Notations do not represent specific objects, as they specify internal structure and relationships among the parts. See Allen, S: Practice: Architecture, Technique and Representation. Amsterdam: G+B Arts International, 2000, p.42

[26] KOOLHAAS, R and Mau, B: Small, Medium, Large, Extra-Large: Office for Metropolitan Architecture. Rotterdam: 010 Publishers, 1995, pp. 1210-1225

[27] Diagram of Geostationary Operational Environmental Satellite (GOES). See http://www.ssec.wisc.edu/media. Accessed 1 May 2008.

[28] CONZEN, M R G: Thanking About Urban Form: Papers on Urban Morphology, 1932-1998. Bern; Oxford: Peter Lang, 2004. 